\title{
Branchial Cleft Remnant
}

National Cancer Institute

\section{Source}

National Cancer Institute. Branchial Cleft Remnant. NCI Thesaurus. Code C104813.

A congenital defect in the neck that occurs during early embryonic development. It is caused by developmental abnormalities of the pharyngeal arches and results in the development of a cyst or a fissure in the side of the neck. 